\title{
Visual Functions in Locally Advanced Nasopharyngeal Carcinoma Patients after External Beam Radiation
}

Imjai Chitapanarux ${ }^{1 *}$, Janejit Choovuthayakorn ${ }^{2}$, Yupa Sumitsawan ${ }^{3}$ and Vicharn Lorvidhaya ${ }^{1}$

${ }^{1}$ Division of Therapeutic Radiology and Oncology, Faculty of Medicine, Chiang Mai University, Thailand

${ }^{2}$ Department of Ophthalmology, Faculty of Medicine, Chiang Mai University, Thailand

${ }^{3}$ Department of Otolaryngology, Faculty of Medicine, Chiang Mai University, Thailand

\begin{abstract}
Purpose: To evaluate the effects of radiation to the anterior visual pathway in locally advanced nasopharyngeal carcinoma (NPC) patients after low energy photon external beam radiation.

Design: A cross-sectional, observational case series

Methods: Fifty- one patients treated with the same radiotherapy were assessed in visual acuity (VA), color vision, visual field (VF), and contrast sensitivity. The patients with post radiation interval of $\leq 3$ years were defined as group 1 , of $>3$ years as group 2 , and healthy volunteers as control group 3 . The visual functions were analyzed between the three groups.

Results: One patient in group 1 developed radiation-induced optic neuropathy (RION) with decreased VA color vision defect, decreased contrast sensitivity, and VF defect. No RION was detected in group 2 . There was no statistical significance in color vision defect $(P=0.303)$ or mean contrast sensitivity $(P=0.235)$ between the three groups. There was statistical significance in mean contrast sensitivity value $(P=0.044)$ between the irradiated and non-irradiated group.

Conclusions: This study reported the acceptable incidence of RION in $1.96 \%$ of locally advanced NPC patients after external beam radiotherapy. Significant decrease in contrast sensitivity was the subclinical anterior visual pathway abnormality, observed among the irradiated group. Monitoring subjective and objective visual changes is helpful for irradiated patients in detecting and assessing treatment for minimizing long term devastating results on the visual conditions.
\end{abstract}

Keywords: Radiation induced optic neuropathy; Locally advanced nasopharyngeal carcinoma; External beam radiotherapy

\section{Introduction}

Nasopharyngeal carcinoma (NPC) is one of the most common cancers in northern Thailand. High numbers of disease-free and overall survival rates, even in the locally advanced stages, have been observed among cancer patients, treated primarily with radiation therapy (RT). The basic principle of this treatment is to deliver a curative dose of RT to the tumor, while minimizing the dose to surrounding structures, especially critical normal organs such as the spinal cord, brainstem, and visual apparatus. In locally advanced NPC, the anterior visual pathways are usually within the radiation field due to their proximity to the base of skull, cavernous sinus, or orbital apex region. While a total dose of 60-70 Gy is required to control a local tumor, the doses of this range may be intolerable and may cause injuries to the anterior visual pathway, thus producing radiation-induced optic neuropathy (RION) [1]. Types of radiation delivery have been reported as contributing factors to RION [2-4]. Several other studies have also reported the relationship between RION and the following factors: dose response, volume response, techniques of radiation, dose fractionation, and quantity of radiation [5-9]. One purpose of this study was to evaluate the visual functions in locally advanced NPC patients, treated with low energy photon external beam radiation therapy (EBRT). The other purpose was to confirm the association of RT and RION as well as to identify which visual function change could potentially be used as an indicator for early detection of RION.

\section{Patients and Methods}

There were 598 patients reported with NPC in the cancer registry at the Faculty of Medicine, Chiang Mai University. A retrospective chart review at the Division of Therapeutic Radiology and Oncology, conducted from January 2002 to December 2007, had identified a number of patients diagnosed with locally advanced NPC staging at T3 or T4 according to the American Joint Committee on Cancer (AJCC) 1992, or T2b and later in accordance with the AJCC 1997. These patients were treated completely following the same radiation protocol.

For each patient, radiotherapy was given with a 6-MV linear accelerator by 2-dimensional techniques, whereby a two-lateral opposing field technique was used to cover the tumor. Defined on the basis of anatomical structures, the primary radiation field margins were the $2-\mathrm{cm}$ peripheries around the CT-detected primary site, and inferiorly down to the thyroid notch to include the lymph nodes. Eyes, brain and brain stem were shielded from the beginning. Once $40 \mathrm{~Gy}$ had been delivered, the spinal cord was then shielded. After that the primary tumor was boosted with an additional $30 \mathrm{~Gy}$ using

*Corresponding author: Imjai Chitapanarux, M.D, Division of Therapeutic Radiology and Oncology, Faculty of Medicine, 110 Intawarorose Road Chiang Mai, 50200, Thailand, Tel: +66-53-945456; Fax: +66-53-945491; E-mail: imjai@hotmail.com

Received February 28, 2012; Accepted April 02-2012; Published April 05-2012

Citation: Chitapanarux I, Choovuthayakorn J, Sumitsawan Y, Lorvidhaya V (2012) Visual Functions in Locally Advanced Nasopharyngeal Carcinoma Patients afte External Beam Radiation. J Nucl Med Radiat Ther 3:126. doi:10.4172/2155 9619.1000126

Copyright: $\odot 2012$ Chitapanarux I, et al. This is an open-access article distributed under the terms of the Creative Commons Attribution License, which permits unrestricted use, distribution, and reproduction in any medium, provided the original author and source are credited. 
$6 \mathrm{MV}$ photons. The posterior upper neck was treated with $10-12 \mathrm{MeV}$ electrons via lateral beam to avoid overexposure of the spinal cord. The brain stem and the eyes were also shielded during the boost phase. A matching anterior low neck field with a midline block of 50 Gy was used to irradiate the supraclavicular lymph nodes. Radiotherapy was delivered in 5 equal fractions per week, with 2 Gy per day.

Included in this study were 51 patients, who showed no evidence of recurrent disease (locoregional or distant), and had no previous history of hypertension, diabetes mellitus, or other ophthalmic diseases that could lead to prior impairment of visual functions. These patients were divided into 2 groups according to their follow-up intervals, i.e. the duration between the first day of radiation therapy and the day of ophthalmologic examination. Group 1 patients included those with shorter than 3 years follow-up intervals and group 2 included all the remainders. Healthy volunteer subjects were recruited as control group 3.

This study was approved by the research ethics committee of the Faculty of Medicine, Chiang Mai University, Thailand. After giving written informed consents, all the patients and the healthy subjects underwent complete ophthalmic examinations conducted between January 2009 and July 2009 by one ophthalmologist and one optometrist using the same processes, the examinations included the following:

- Best corrected visual acuity (BCVA) by a Snellen acuity chart;

- Anterior segment and fundus evaluation;

- Intraocular pressure measurement using a Goldmann applanation tonometer;

- Visual field (VF) testing by an automatic Humphrey Field Analyser, model 750 (Carl Zeiss Meditec, Dublin, CA, USA) with The Swedish Interactive Threshold Algorithm (SITA) standard 30-2, white on white program (1 absolute scotoma or 3 consecutive relative scotomas defined as visual field defects);

- Color vision testing by Ishihara plates (the corrected reading value of less than 8 was defined as color vision defect); and

- Contrast sensitivity testing by a Pelli Robson chart.

\section{Statistical analysis}

Visual parameters were compared among the groups by adopting the Mann-Whitney $U$ test for continuous variables and chi-square test for categorical variables. All analyses were conducted using SPSS

\begin{tabular}{|l|l|l|l|}
\hline & Group 1 & Group 2 & Group 3 \\
\hline Patients $(\mathrm{n})$ & 29 & 22 & 31 \\
\hline Eyes $(\mathrm{n})$ & 58 & 44 & 62 \\
\hline $\begin{array}{c}\text { Sex (n) } \\
\text { Male } \\
\text { Female }\end{array}$ & 18 & 17 & 9 \\
\hline $\begin{array}{c}\text { Age (yr) } \\
\text { Median } \\
\text { Range }\end{array}$ & 11 & 5 & 22 \\
\hline Eyes with visual acuity <6/60 (\%) & $2 / 58(3.4)$ & $2 / 44(4.5)$ & 0 \\
\hline Eyes with color vision defect (\%) & $3 / 58(5.1)$ & $1 / 44(2.2)$ & 0 \\
\hline $\begin{array}{c}\text { Eyes with visual field defect (\%) } \\
\text { Contrast Sensitivity (log unit) } \\
\text { Mean } \\
\text { Range }\end{array}$ & $2 / 58(3.4)$ & $0 / 22(0)$ & 0 \\
\hline
\end{tabular}

Table 1: Demographic data of the patients in 3 groups. software (SPSS, Inc, Chicago, Illinois, USA). P values of $\leq 0.05$ were considered statistically significant.

\section{Results}

Table 1 summarizes the demographic data of the patients and the healthy subjects as well as their visual functions. Group 1 enrolled 29 patients ( 58 eyes). Eighteen males and eleven females, with ages ranged from 11 to 72 years old, made up this group. The mean age was 46.7 and the median age was 47.0 years. The follow-up times were between 8 months and 35 months, with mean and median of 19.6 and 17.0 months respectively. Constituting 3.4\%, one patient showed evidence of RION development (in both eyes) with visual acuity (VA) of equal to or less than $6 / 60$, color vision defect, and cecocentral absolute scotoma visual field defect. Another patient showed color vision defect in one eye. The contrast sensitivity value for this group ranged from 1.35 to 1.95 in log unit, with mean and median of 1.60 and 1.54 respectively.

Group 2 enrolled 22 patients (44 eyes). With ages ranged from 17 to 65 years old, seventeen were male and five were female. The mean age and the median age were 46.5 and 48.0 years respectively. The follow-up times were between 37 and 72 months, with mean value of 49.4 and median value of 48.0 months. None of these patients was diagnosed as RION and none of them had developed visual field defect. Two patients had VA of less than 6/60 in both eyes, and one patient had color vision defect in one eye. These represent $4.5 \%$ in poor VA incidences and $2.2 \%$ in color vision defect incidences. The range, mean, and median contrast sensitivity values for this group were 1.50-1.95, 1.57 , and 1.52 respectively.

Group 3 enrolled nine male and 22 female healthy subjects (62 eyes). The age range, mean age, and median age were $24-59,35.5$, and 39.0 years respectively. All of these subjects had VA of equal to or better than 6/12. None showed color vision defect or visual field defect. The contrast sensitivity range for this group 3 was $1.65-1.95$, with mean of 1.79 and median of 1.80 .

While there was no statistical significance in color vision defect $(P=0.303)$ or mean contrast sensitivity $(P=0.235)$ among the three groups, there was statistical significance in mean contrast sensitivity value ( $P=0.044$ ) between the irradiated and non-irradiated group.

\section{Discussion}

Normal ocular tissue has a spectrum of radiation tolerance. The lacrimal system, lens, eyelashes, retina, and anterior visual pathway are ophthalmic radiosensitive structures. The optic nerve has a higher risk for RION compared to other cranial nerves, due to its myelination by oligodendrocytes, which are radiosensitive. RION has been reported as an uncommon post-radiation visual abnormality [9-11]. The interval between irradiation and the development of visual function impairment ranged from 3 months to over 8 years [1,9]. Early onset of RION has been thought to come from acute inflammation, [11] and late onset from endothelial cell damage, fibrinoid necrosis and ischemic injuries of the tissue [12]. Most cases occurred within 3 years, with peak incidences at 1 to 1.5 years[13,14] The maximum dose of visual apparatus tolerance was reported, with a tendency to reduce complications at a dose of less than 50-60 Gy and fraction sizes of less than 2 Gy [15-17]. In patients with pituitary tumors, a lower tolerance dose of optic nerve has been reported and RION can occur after a considerable latency period ( 5 months - 10 years) [18]. The patients in this study received an RT dose range of 66-70 Gy, with a fraction size of $2 \mathrm{~Gy}$ per day which was higher than the tolerance dose of 50 - $65 \mathrm{~Gy}$ of optic nerve and chiasm. One patient in this study, after treated with 
Citation: Chitapanarux I, Choovuthayakorn J, Sumitsawan Y, Lorvidhaya V (2012) Visual Functions in Locally Advanced Nasopharyngeal Carcinoma Patients after External Beam Radiation. J Nucl Med Radiat Ther 3:126. doi:10.4172/2155-9619.1000126

low energy photon external beam radiation, developed post-radiation bilateral RION after 22 months. This $2 \%$ occurrence suggested an acceptable RION incidence. Various pathologic vascular conditions such as diabetes mellitus or hypertension have been attributed as risk factors for RION $[5,19,20]$. However, this study reported an incidence of RION in patients with no influence from vascular compromised conditions. Esassolak et al. concluded that radiation-induced injury to the anterior visual pathways could result in an increase in VEP latency and a decrease in VEP amplitude and contrast sensitivity in locally advanced nasopharyngeal carcinoma patients who treated with high dose radiotherapy [21]. Change in subjective visual functions, such as visual field and contrast sensitivity, should be regarded as an indication of subclinical damage to the anterior visual pathway. In most community-based hospitals, this visual change could be monitored so that each involved NPC patient can be forewarned. This study showed a statistically significant decrease in contrast sensitivity among the irradiated groups when compared with the normal group. However, no statistically significant difference of visual field was observed among the three groups.

The therapeutic options for RION, including corticosteroid, anticoagulant or hyperbaric oxygen, showed variable visual outcomes with little benefit [11]. Anti-vascular endothelial growth factor (VEGF), the drug reported in past studies, has been used recently through intravitreal injection in early RION and has shown improvement in the visual acuity [22]. Careful monitoring of both subjective and objective clinical visual function is crucial in detecting immediate visual pathway injuries, which will allow for an early intervening attempt to recover or stabilize the vision after treatment.

The limitations of this study were the retrospective nature, small number of patients, and one time point evaluation of visual functions.

\section{Conclusion}

This study indicated an acceptable RION incidence of $1.96 \%$ among locally advanced NPC patients, treated with a fraction size of 2 Gy external beam radiation. Significant decrease in contrast sensitivity was the subclinical anterior visual pathway abnormality, observed among the irradiated group. The changes in this visual function could be monitored regularly in most community-based hospitals. Visual examination program should be offered to all NPC patients as an integral part of the radiotherapy protocol. Early detection of functional visual impairment and immediate subsequent treatment are effective strategies for minimizing long term devastating results on the visual conditions.

\section{References}

1. Kline LB, Kim JY, Ceballos R (1985) Radiation optic neuropathy. Ophthalmology 92: 1118-1126

2. Parsons JT, Bova FJ, Fitzgerald CR, Mendenhall WM, Million RR (1994) Radiation optic neuropathy after megavoltage external-beam irradiation: analysis of time-dose factors. Int J Radiat Oncol Biol Phys 30: 755-763.

3. Stafford SL, Pollock BE, Leavitt JA, Foote RL, Brown PD, et al (2003) A study on the radiation tolerance of the optic nerves and chiasm after stereotactic radiosurgery. Int J Radiat Oncol Biol Phys 55: 1177-1181.

4. Demizu Y, Murakami M, Miyawaki D, Niwa Y, Akagi T, et al. (2009) Analysis of vision loss caused by radiation-induced optic neuropathy after particle therapy for head-and-neck and skull base tumors adjacent to optic nerves. Int J Radiat Oncol Biol Phys 75: 1487-1492.

5. Brown GC, Shields JA, Sanborn G, Augsburger JJ, Savino PJ, et al. (1982) Radiation optic neuropathy. Ophthalmology 89: 1489-1493.
6. Jiang GL, Tucker SL, Guttenberger R, Peters LJ, Morrison WH, et al. (1994) Radiation-induced injury to the visual pathway. Radiother Oncol 30: 17-25.

7. Bhandare N, Monroe AT, Morris CG, Bhatti MT, Mendenhall (2005) Does altered fractionation influence the risk of radiation-induced optic neuropathy? Int J Radiat Oncol Biol Phys 62: 1070- 1077.

8. Danesh-Meyer H (2008) Radiation-induced optic neuropathy. J Clin Neurosc 15: $95-100$.

9. Durkin SR, Roos D, Higgs B, Casson RJ, Selva D (2007) Ophthalmic and adnexal complications of radiotherapy. Acta Ophthalmol Scand 85: 240- 250.

10. Finger PT (2009) Radiation therapy for orbital tumors: concepts, current use and ophthalmic radiation side effects. Surv Ophthalmol 54: 545- 568.

11. Miller NR (2004) Radiation-induced optic neuropathy: still no treatment. Clin Experiment Ophthalmol 32: 233- 235.

12. Levin LA, Gragoudas ES, Lessell S (2000) Endothelial cell loss in irradiated optic nerves. Ophthalmology 107: 370-374.

13. Roden D, Bosley TM, Fowble B, Clark J, Savino PJ, et al. (1990) Delayed radiation injury to the retrobulbar optic nerves and chiasm. Clinical syndrome and treatment with hyperbaric oxygen and corticosteroids. Ophthalmology 97 346-351.

14. McClellan R, el Gammal T, Kline LB (1995) Early bilateral radiation-induced optic neuropathy with follow-up MRI. Neuroradiology 37: 131-133.

15. Martel MK, Sandler HM, Cornblath WT, Marsh LH, Hazuka MB, et al. (1997) Dose-volume complication analysis for visual pathway structures of patients with advanced paranasal sinus tumors. Int J Radiat Oncol Biol Phys 38: 273284

16. Daly ME, Chen AM, Bucci MK, El-Sayed I, Xia P, et al (2007) Intensitymodulated radiation therapy for malignancies of the nasal cavity and paranasal sinuses. Int J Radiat Oncol Biol Phys 67: 151-157.

17. Mayo C, Martel MK, Marks LB, Flickinger J, Nam J, et al. (2010) Radiation dose-volume effects of optic nerves and chiasm. Int J Radiat Oncol Biol Phys 76: S28-35.

18. Van den Bergh AC, Hoving M,A Links TP, Dullaart RP, Ranchor AV, et a (2003) Radiation optic neuropathy after external beam radiation therapy for acromegaly: report of two cases. Radiother Oncol 68: 101-103.

19. Chan RC, Shukovsky LJ (1976) Effects of irradiation on the eye. Radiology 120: $673-675$

20. Emami B, Lyman J, Brown A, Coia L, Goitein M, et al (1991) Tolerance of normal tissue to therapeutic irradiation. Int J Radiat Oncol Biol Phys 21: 109122.

21. Esassolak M, Karagoz U, Yalman D, Kose S, Anacak Y, et al. (2004) Evaluation of the effects of radiotherapy to the chiasm and optic nerve by visual psychophysical and electrophysiologic tests in nasopharyngeal carcinoma. In J Radiat Oncol Biol Phys 58: 1141-1146.

22. Finger PT (2007) Anti-VEGF bevacizumab (Avastin) for radiation optic neuropathy. Am J Ophthalmol143: 335-338. 